\title{
Surface modification of sapphire by ion implantation
}

\section{CONF-980764 .}

\author{
Carl J. McHargue \\ Center for Materials Processing, University of Tennessee, Knoxville, TN 37996 \\ AUG 131998

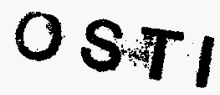 \\ ABSTRACT
}

RECEIVED

\begin{abstract}
The range of microstructures and properties of sapphire (single crystalline $\mathrm{Al}_{2} \mathrm{O}_{3}$ ) that are produced by ion implantation are discussed with respect to the implantation parameters of ion species, fluence, irradiation temperature and the orientation of the ion beam relative to crystallographic axes. The microstructure of implanted sapphire may be crystalline with varying concentrations of defects or it may be "amorphous", perhaps with short-range order. At moderate to high fluences, implanted metallic ions often coalesce into "pure" metallic colloids and gas ions form bubbles. Many of the implanted microstructural - features have been identified from studies using transmission electron microscopy (TEM), optical spectroscopy, Mössbauer spectroscopy, and Rutherford backscattering-channeling. The chemical, mechanical, and physical properties reflect the microstructures.
\end{abstract}

Keywords: ion implantation, sapphire, optical properties, defect structures, microstructure, metallic colloids

\section{INTRODUCTION}

The process of ion implantation is nonequilibrium in nature and introduces ion species and defects into a solid without regard to thermodynamic or thermochemical factors; however, the response of the target does reflect its chemical and structural nature. The microstructure that remains after the cascade cool-down period and subsequent changes in microstructure with time or temperature are driven towards the equilibrium conditions.

Interactions of the ion beam with ceramics are more complex than for metals or elemental semiconductors. Ceramics are compounds with two or more chemical species that are distributed over at least two sublattices in an ordered manner. In many instances, atoms displaced during elastic collisions are not likely to come to rest at the lattice sites of the other type. The species have different atomic masses and the energy to displace each from its lattice site may be different. For example, the energy to displace an aluminum ion in sapphire has been reported to be 18 to $32 \mathrm{eV}$ and to displace an oxygen ion, 41 to $76 \mathrm{eV}^{1}$.

The above factors determine the manner in which the energy that is dissipated by elastic collisions is partitioned among the target atoms (ions) and, thus, the production of defects. The type of chemical bonding determines the types of defects that exist after the cascade cool-down period. In many insulators, the introduction of a defect or an impurity ion must occur in a manner that maintains overall electrical neutrality; consequently, the point defects may carry an effective charge or impuritypoint defect complexes may be introduced.

Although there have been indications for many years that the ionizing component of the irradiation spectrum affects the residual stress and the volumetric changes in irradiated oxides, such effects have been generally ignored. It was argued that the high values of $E_{d}$ make it unlikely that defects will be produced in most ceramics by ionizing or excitation processes at the energies commonly used in ion implantation. In 1964, Walker noted that electron-irradiation reduced the sweiling that had been produced by neutron irradiation of $\mathrm{BeO}^{2}$. Kreft et al. noted features of ion-irradiated $\mathrm{Al}_{2} \mathrm{O}_{3}, \mathrm{MgO}$ and $\mathrm{SiO}_{2}$ that seemed to be caused by the ionizing component: the level of damage saturated when the ionizing component of the bombarding ion beams was high but not when it was low; residual stresses in ion-implanted samples were reduced when the samples were subsequently irradiated with protons; and, light ions produced less volume swelling (damage) per dpa (displacements per atom) than heavy ions ${ }^{3-6}$. Zinkle ${ }^{7-10}$ has noted that the ionizing component has significant effects on the microstructures of $\mathrm{Al}_{2} \mathrm{O}_{3}, \mathrm{MgO}$, and $\mathrm{MgAl}_{2} \mathrm{O}_{4}$ (spinel) due to radiation-induced diffusion processes and ionization-enhanced point defect recombination. In these studies, a high ionizing component suppressed dislocation loop formation and enhanced loop growth. Microstructures often exhibited defect denuded zones adjacent to grain boundaries and free surfaces.

"The submitted manuscript has been authored by a contractor of the U.S. Government under contract No. DE-AC05-960R22464. Accordingly, the U.S. Government retainsto nonexclusive, royalty-free license

to publish or reproduce the published

form of this contribution, or allow others 


\section{DISCLAIMER}

This report was prepared as an account of work sponsored by an agency of the United States Government. Neither the United States Government nor any agency thereof, nor any of their employees, makes any warranty, express or implied, or assumes any legal liability or responsibility for the accuracy, completeness, or usefulness of any information, apparatus, product, or process disclosed, or represents that its use would not infringe privately owned rights. Reference herein to any specific commercial product, process, or service by trade name, trademark, manufacturer, or otherwise does not necessarily constitute or imply its endorsement, recommendation, or favoring by the United States Government or any agency thereof. The views and opinions of authors expressed herein do not necessarily state or reflect those of the United States Government or any agency thereof. 


\section{DISCLAIMER}

Portions of this document may be illegible in electronic image products. Images are produced from the best available original document. 


\section{IMPLANTATION OF SAPPHIRE (SINGLE CRYSTAL $\mathrm{Al}_{2} \mathrm{O}_{3}$ )}

\subsection{Structure of Sapphire}

Sapphire belongs to the space group $\mathrm{R} 3 \mathrm{C}$ (rhombohedral). The $\mathrm{O}^{2-}$ anions are arranged in an approximately hexagonal closepacked array with the $\mathrm{Al}^{3+}$ cations occupying $2 / 3$ of the available octahedral sites in an ordered arrangement. The structure has trigonal symmetry in the basal plane and the a-axes are fixed by the ordered vacant Al-sites. The structure has often been described on the basis of the close-packing of oxygen ions although there are significant deviations from the ideal hap structure which are related to the electrostatic interactions between the ions. The aluminum ions and holes are arranged to give maximum separation of like charges and a minimum separation of unlike charges, consistent with the bonding between aluminum and oxygen and the maintenance of overall electrical neutrality. According to the Pauling Electronegativity criterion, the chemical bonding of sapphire is $63 \%$ ionic in nature.

Although many oxides exhibit deviations from stoichiometry (some as much as several percent), any departure from stoichiometry in sapphire is so small that it cannot be detected by current analytical procedures. Consequently, while it is possible to substitute $3+$ impurities for $\mathrm{Al}^{3+}$, impurities cannot be added without creating charge-compensating defects. The vacant octahedral sites are "structural vacancies" and are ordered to maintain the electrostatic forces in the crystal. The free energy of formation for sapphire is among the most negative of any oxide (other than a few rare earth oxides); thus, in any reaction involving displaced or implanted ions with oxygen, the formation of $\mathrm{Al}_{2} \mathrm{O}_{3}$ will be favored.

\subsection{Effects of implantation parameters on the structure of implanted sapphire}

The structure of ion implanted sapphire depends upon the implantation parameters or ion fluence, ion species, substrate temperature and the orientation of the ion beam relative to the crystallographic axes. Ion energy in the range of $50 \mathrm{keV}$ to $1-2$ $\mathrm{MeV}$ appears to have little effect on the displacement damage except to determine the depth distribution of the irradiationproduced defects and the implanted species.

Many studies have found that room temperature implantation of many ions (e. g., $\mathrm{Al}, \mathrm{Ti}, \mathrm{Cr}, \mathrm{Mn}, \mathrm{Fe}, \mathrm{Ni}, \mathrm{Cu}, \mathrm{Ga}, \mathrm{Nb}, \mathrm{Mo}$ ) produces extensive damage in the near-surface region. This region remains crystalline unless very high fluences or very high values of deposited damage energy density are used. For a review of the studies conducted prior to 1989 see reference 11. Damage (disorder) is often determined from Rutherford backscattering-channeling measurements and represented as $\chi$ for the Al-sublattice determined at the position of peak damage. The quantity $\chi$ is defined as the ratio of backscattered yield from an aligned (channeling) specimen to that from a randomly oriented specimen. Damage accumulates rapidly at low fluences but typically remains relatively constant for values of peak deposited damage energy (DE) in the range of about 1 to $9 \mathrm{keV} /$ atom. This behavior is illustrated in Fig. 1 for implantation of $\mathrm{Cr}, \mathrm{Fe}, \mathrm{Nb}$ and $\mathrm{Ti}$ into sapphire with the ion beam oriented about $7^{\circ}$ from the c-axis. The data were normalized in terms of deposited damage energy as calculated using the code E-DEP-1 (P5.0) ${ }^{12}$. These data suggest that dynamic recovery accompanies the production of defects and that the rate of recovery is similar to that of defect production once some background level of defects is reached.

The amount of residual lattice damage again increases at higher values of DE. For example, Bull ${ }^{13}$ found an amorphous surface $(\chi=1)$ for sapphire crystals having the $\left\{\begin{array}{llll}1 & 0 & \overline{1} & 2\end{array}\right\}$ face implanted with $6 \times 10^{17} \mathrm{Cr} / \mathrm{cm}^{2}$. These conditions correspond to a peak damage energy deposition $\approx 50 \mathrm{keV} /$ atom and a chromium concentration equal to half the $\mathrm{Al}$ concentration. Ren et al. ${ }^{14}$ reported that (0001) surfaces implanted with $160 \mathrm{keV}$ Fe became amorphous at a fluence between $1 \times 10^{17}$ and $2 \times 10^{17}$ $\mathrm{Fe} / \mathrm{cm}^{2}$, i.e., $\mathrm{DE}$ between 10.7 and $21.4 \mathrm{keV} /$ atom.

Amorphization can also occur during room temperature implantation with low to moderate fluences of a few chemical species where it appears to be due to unidentified "chemical" effects. For example, implanting ${ }^{90} \mathrm{Zr}$ and ${ }^{93} \mathrm{Nb}$ to the same fluence at similar energy deposition densities give different amounts of disorder ${ }^{11.15}$. Since these elements differ by only three atomic mass units, the details of the cascades should be similar; hence, the differences in the disorder appears to originate in some chemical effect during the cool-down period or to an inhibition of defect recovery. Figure 2 contains the RBS spectra for samples implanted with $\mathrm{Zr}(6.98 \mathrm{keV} / \mathrm{atom})$ and $\mathrm{Nb}(6.9 \mathrm{keV} / \mathrm{atom})$. The $\mathrm{Zr}$-implantation produced an amorphous layer extending to about $110 \mathrm{~nm}$ below the surface. (The surface of the $\mathrm{Zr}$-implanted sample was amorphous at a 


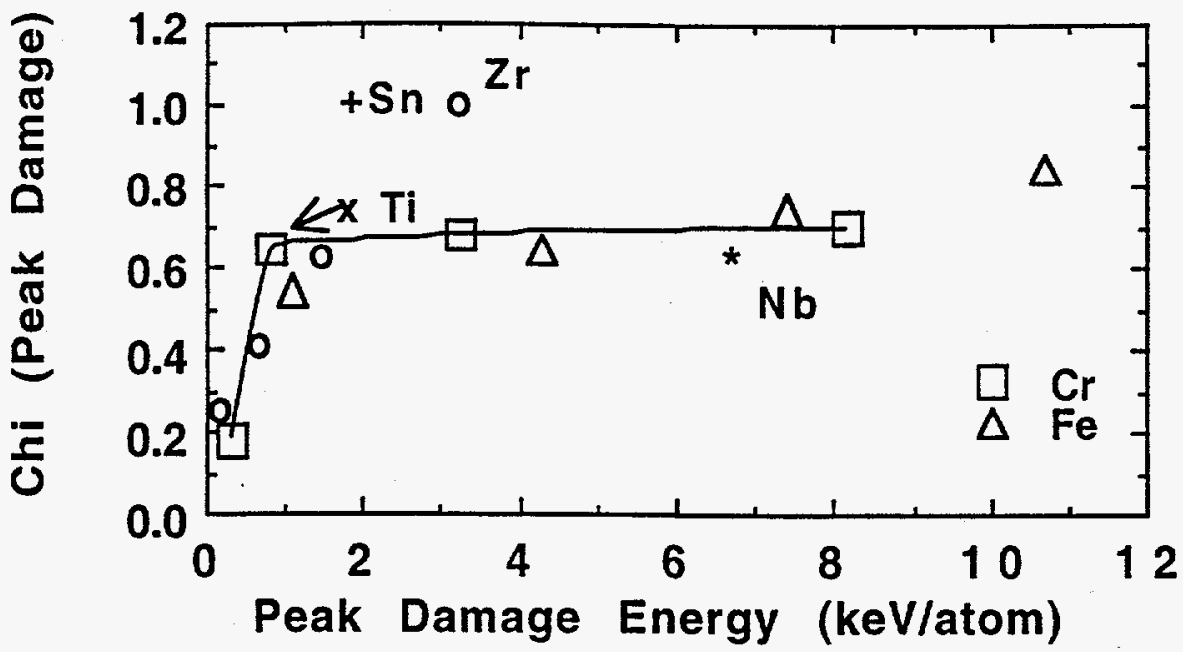

Fig. 1. Peak damage in the Al-sublattice as a function of damage energy

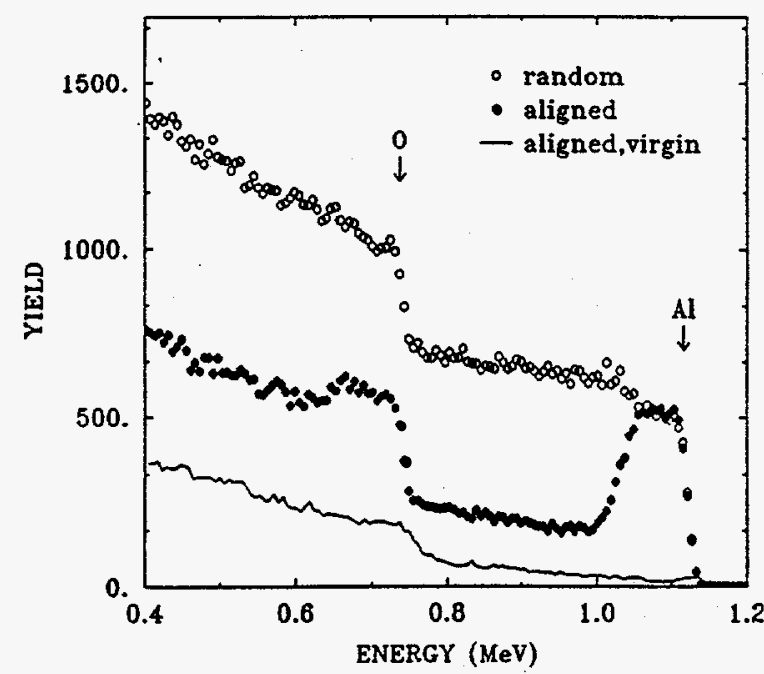

(a)

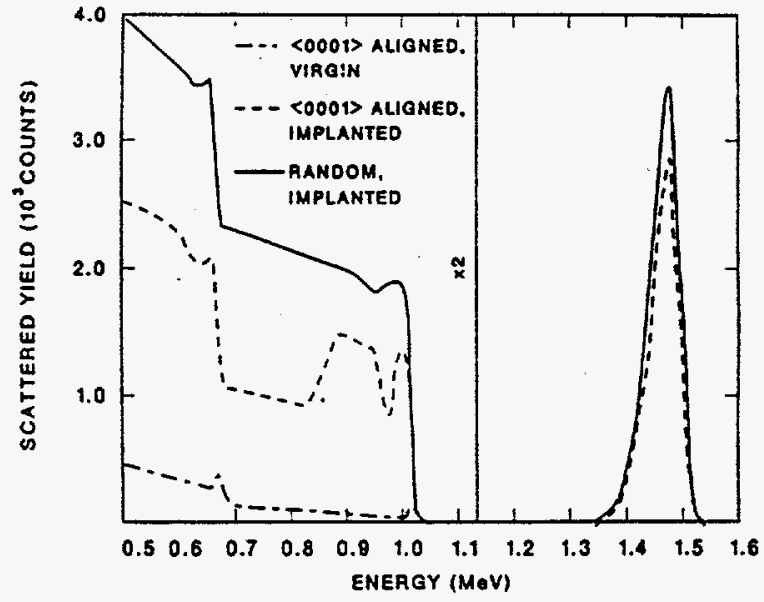

(b)

Fig. 2. Backscattering spectra from $\mathrm{Al}_{2} \mathrm{O}_{3}$ implanted with (a) $4 \times 10^{16}{ }^{90} \mathrm{Zr}$ ions $/ \mathrm{cm}^{2}$ (175 keV) and (b) $4 \times 10^{16}{ }^{93} \mathrm{Nb}$ ions $/ \mathrm{cm}^{2}(220 \mathrm{keV})$.

$\mathrm{DE}$ level of $3.49 \mathrm{keV} /$ atom.) The RBS spectra for the $\mathrm{Nb}$-implanted crystal indicate only a damaged surface region with $\chi$ for the Al-sublattice reaching a maximum value of 0.64 .

An analytical electron microscopy study ${ }^{16}$ suggested that amorphization may have occurred at a critical concentration. Measurements of the $\mathrm{Zr}$-concentration profile were made in a series of cross-sectioned specimens which had been implanted to 
give buried amorphous layers of different widths. The positions of the boundaries of the amorphous region corresponded to a $\mathrm{Zr} / \mathrm{Al}$ atomic fraction of $\sim 0.065$ but exhibited no correlation with damage energy deposition profiles, i.e., defect production.

Other ion species that produce amorphous layers at relatively low fluences during room temperature implantation are $\mathrm{Sn}{ }^{17}$, $\mathrm{Zn}{ }^{11}, \mathrm{Si}^{11}$ and $\mathrm{C}^{11}$. The accumulation of damage in the Al-sublattice as a function of deposited damage energy is indicated in Fig. 1 for $\mathrm{Zr}$ and $\mathrm{Sn}$.

The RBS-C spectra for $\mathrm{Cr}$ implanted into sapphire $\left(150 \mathrm{keV}, 4 \times 10^{16}\right.$ ions $\left./ \mathrm{cm}^{2}\right)$ at substrate temperatures of 77,300 , and about $640 \mathrm{~K}$, Fig. 3, show that the higher the substrate temperature during implantation, the lower the residual disorder or damage ${ }^{18}$. The peak damage in the Al-sublattice is similar for the 300 and $640 \mathrm{~K}$ implantations but the disorder in the region from the surface to the peak position is less at the higher temperature. The free surface may be acting as a sink for the irradiation-produced defects.

As indicated by the RBS-C spectra of Fig. 3, implantation at low substrate temperatures $(<100 \mathrm{~K})$ produces an amorphous or random state. The random value of backscattered yield for the Al-sublattice is reached at $0.32 \mathrm{keV} / \mathrm{atom}$ for $260 \mathrm{keV} \mathrm{Cr}$ implantation at $77 \mathrm{~K}$ (c-axis orientation). Transmission electron microscopy and selected area diffraction patterns confirmed the amorphous nature of the implanted zone, i. e., no coherently diffracting regions greater than $1 \mathrm{~nm}$ in size. Figure 4 compares the disorder, $\chi$, in the Al-sublattice as a function of deposited damage energy for $\mathrm{Cr}$ implantation at $77 \mathrm{~K}$ (liquid nitrogen temperature, LNT) with that at $300 \mathrm{~K}$. That the amorphization is due to damage accumulation and not chemical effects has been confirmed by stoichiometric implants of aluminum plus oxygen at $77 \mathrm{~K}$. Abe et al. ${ }^{19}$ detected amorphous regions in thin foils of sapphire irradiated with xenon and krypton ions at temperatures below $200 \mathrm{~K}$. Since almost all the ions passed through the foils, the amorphization was attributed to damage accumulation.

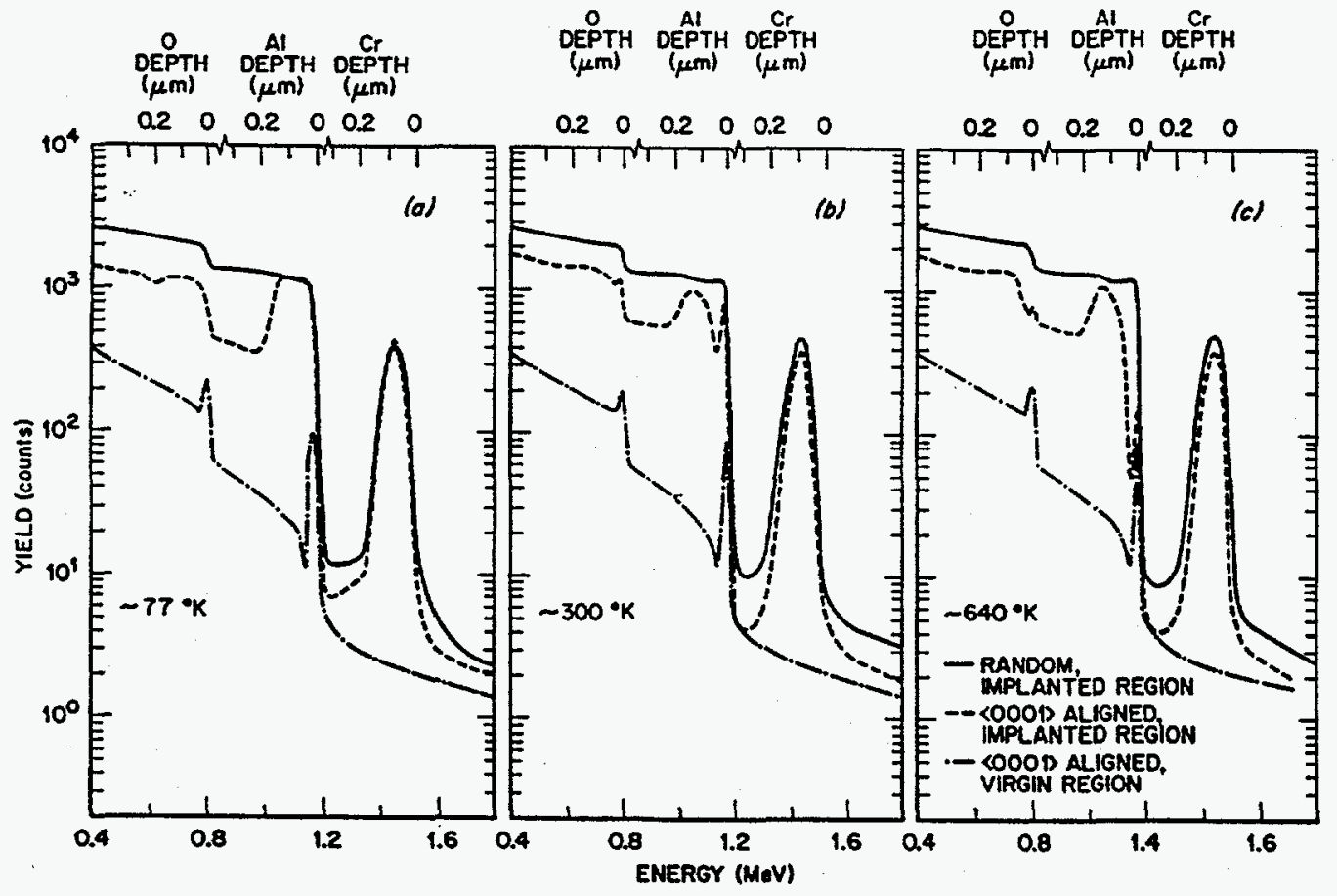

Fig. 3. Rutherford backscattering-ion channeling spectra for sapphire implanted with $4 \times 10^{16} \mathrm{Cr} / \mathrm{cm}^{2}(150 \mathrm{keV})$ at different substrate temperatures (from reference 30 ). 


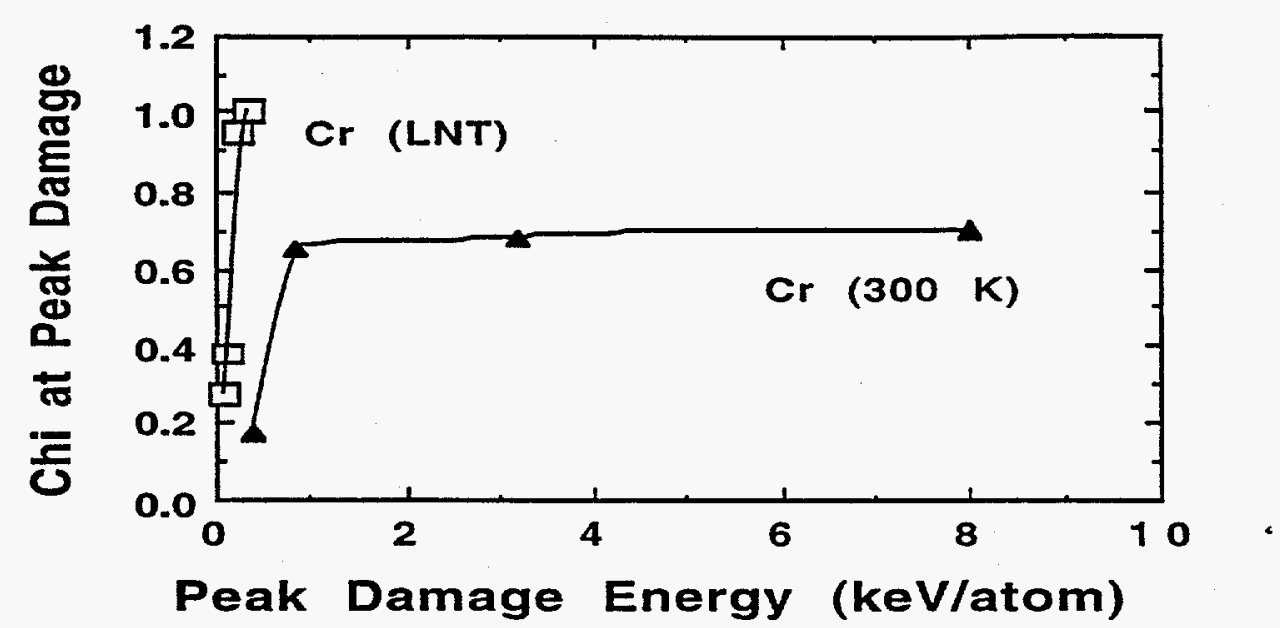

Fig. 4. Damage accumulation at 77 and $300 \mathrm{~K}$ in $\mathrm{Cr}$-implanted sapphire

The amount of residual disorder is strongly dependent upon the orientation of the ion beam relative to the crystallographic axes, especially at higher fluences ${ }^{20,21}$. This observation may explain some of the differences in implanted structures reported by different investigators who often have used specimens of different orientations. Figure 5 shows the accumulation of peak lattice disorder at room temperature as a function of fluence for sapphire implanted with $160 \mathrm{keV}$ iron. In each case, the a- or $\mathrm{c}$-axis was oriented about $7^{\circ}$ from the beam axis in order to avoid channeling during implantation. The amount of disorder is similar at fluences below $4 \times 10^{16}$ ions $/ \mathrm{cm}^{2}$ but the disorder accumulates much faster for the $\mathrm{c}$-axis specimens at higher fluences. For these conditions, the random (amorphous) state is reached at $2 \times 10^{17} \mathrm{Fe} / \mathrm{cm}^{2}$ for the c-axis specimen but this condition had not been reached in the a-axis material at $5 \times 10^{17} \mathrm{Fe} / \mathrm{cm}^{2}$.

Studies ${ }^{20}$ on $\mathrm{Cr}$ implantation at $77 \mathrm{~K}$ have shown that the random state is reached at a fluence of $2-3 \times 10^{15} \mathrm{Cr} / \mathrm{cm}^{2}$ for the c-axis specimens but only at a fluence of $2.4 \times 10^{16} \mathrm{Cr} / \mathrm{cm}^{2}$ for the a-axis samples, an order of magnitude difference. The RBS-C measurements indicated a difference in the manner in which the disorder accumulated.

Bull ${ }^{13}$ and $\mathrm{O}^{\prime} \mathrm{Hern}$ et al. ${ }^{22}$ observed that the measured residual stresses and the hardness changes were lower at a given fluence for the a-axis orientation.

\subsection{Structure of ion implanted sapphire}

Rutherford backscattering-ion channeling (RBS-C) measurements suggest that the stoichiometry of sapphire does not change during implantation of at least some ionic species ${ }^{23-26}$. Channeling yield measurements support the conclusion that the number of residual aluminum and oxygen displaced ions occur in the stoichiometric ratio for implantation of Xe and $\mathrm{Pt}^{23}$, $\mathrm{Pb}^{24,25}$ and $\mathrm{Al}^{26}$.

Transmission electron micrographs and selected area diffraction (SAD) patterns for sapphire implanted with cations at room - temperature are characterized by a high density of "black spots" typical of point defect clusters. It is likely that they are stoichiometric, interstitial dislocation loops. Zinkle ${ }^{27}$ identified dislocation loops on $\{0001\}$ and $\left\{\begin{array}{lllll}1 & 0 & \overline{1} & 0\end{array}\right\}$ habit planes for samples implanted to a peak damage energy of $3.1 \mathrm{keV} /$ atom with simultaneous beams of $\mathrm{Al}$ and oxygen at room temperature. The Burgers vector was $b=1 / 3<0 \quad 1 \quad \overline{1} l>$ for many of the dislocations. 


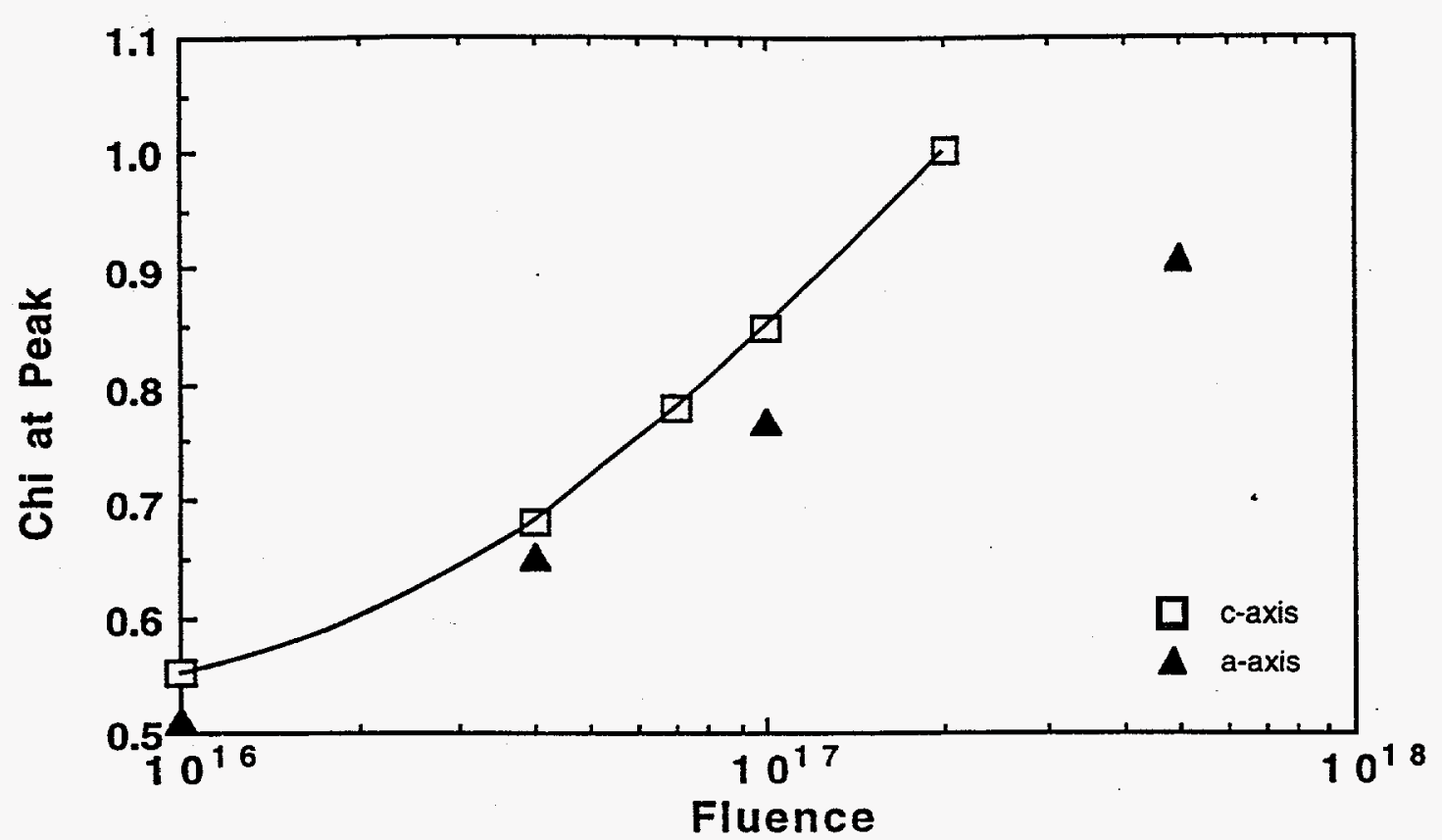

Fig. 5. Damage as a function of iron fluence for $c$-axis and a-axis oriented sapphire

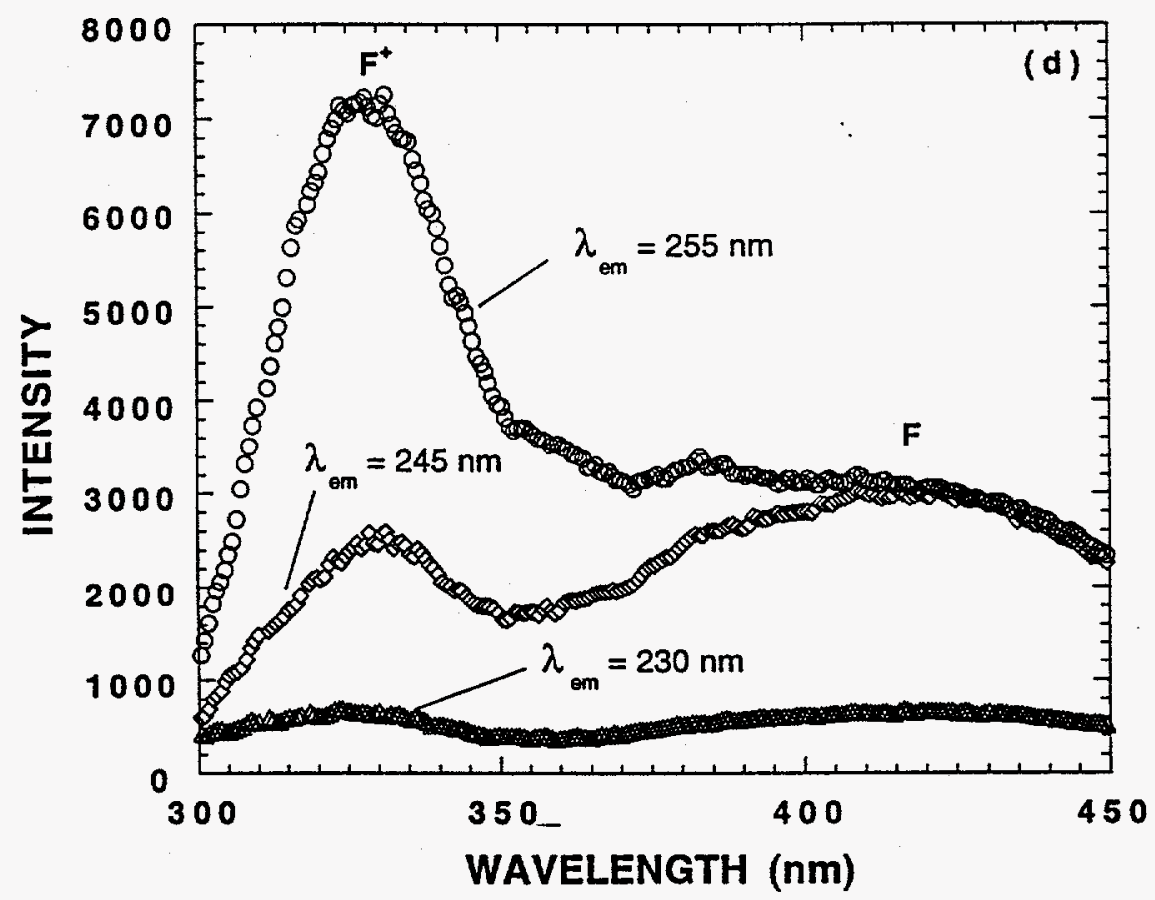

Fig. 6. Luminescence spectra of sapphire implanted with $4 \times 10^{16} \mathrm{Fe} / \mathrm{cm}^{2}(160 \mathrm{keV})$ excited by indicated wavelengths. 
Defects in the anion sublattice can be detected by optical spectroscopy. Samples implanted with cations at room temperature have a characteristic gray-brown color. Optical density (absorption) spectra ${ }^{14}$ are characterized by a strong peak in the vicinity of $200 \mathrm{~nm}$ (from about 170 to $230 \mathrm{~nm}$ ) in specimens implanted with 4 to $10 \times 10^{16} \mathrm{Fe} / \mathrm{cm}^{2}$. This region contains the location of both $\mathrm{F}$ and $\mathrm{F}^{+}$peaks, an oxygen vacancy containing two trapped electrons and an oxygen vacancy containing one trapped electron, respectively. These defects have peaks in the emission spectra at 406 and $331 \mathrm{~nm}$, respectively. The luminescence curves of Fig. 6 clearly show the presence of both types of anion defects in a sample implanted with $4 \times 10^{16}$ $\mathrm{Fe} / \mathrm{cm}^{2}$.

Information about the final disposition of the implanted ions can be determined from RBS-channeling measurements if the disorder is relatively low, e. g., at low fluences or in annealed samples. Canera et al ${ }^{25}$ used axial and planar scans to determine that lead ions implanted into $\mathrm{Al}_{2} \mathrm{O}_{3}$ occupied sites along the $<0001>$ rows but displaced $0.05 \mathrm{~nm}$ from the oxygen planes.

The Mössbauer effect provides a unique probe for investigating the structural aspects of solids on the atomic scale. Measurements of the hyperfine interactions provide information on symmetry, ordering, and chemical bonding in the immediate environment of the probed nucleus.

A combined RBS, TEM, and Conversion Electron Mössbauer Spectroscopy (CEMS) study ${ }^{28}$ has determined the residual charge state on iron ions implanted into sapphire at room temperature to fluences of $10^{16}$ to $10^{17} \mathrm{Fe} / \mathrm{cm}^{2}$. The matrix remained crystalline for these conditions. Five quadrupole-split doublets and one single line were detected. The doublets were ascribed to three types of ferrous iron $\left(\mathrm{Fe}^{2+}\right)$ and two forms of the high spin state $\mathrm{Fe}^{4+}$. The single line was identified as arising from metallic iron clusters $\left(\mathrm{Fe}^{0}\right)$.

The $\mathrm{Fe}^{2+}$ components were ascribed to isolated or clusters of a few implanted iron ions associated with one to a few oxygen vacancies. The single line was attributed to small metallic precipitates that behave superparamagnetically at room temperature but show magnetic splitting at $4 \mathrm{~K}$. Precipitate particles having a size of $1-3 \mathrm{~nm}$ were detected by TEM examination and electron diffraction patterns indicate the precipitate to be $\alpha-\mathrm{Fe}$, Fig. 7a. The CEMS results indicate that they are under high hydrostatic pressure.

The high-spin state, $\mathrm{Fe}^{4+}$, appears only at higher fluences. This state appears to arise from iron ions located in tetragonallydistorted octahedra which contain oxygen vacancies or nonbridging oxygen ions.

The relative amount of each state depends upon the implantation fluence (concentration of iron and amount of damage). At the lowest fluence studied, all the iron is distributed among the three $2+$ states. The $\mathrm{Fe}^{0}$ state appears at higher fluences and constitutes almost $40 \%$ of the iron at $10^{17} \mathrm{Fe} / \mathrm{cm}^{2}$. The $\mathrm{Fe}^{4+}$ state is present only at high fluences where the disorder is high and there are large numbers of oxygen vacancies.

One of the $\mathrm{Fe}^{2+}$ components present in the room temperature Fe-implanted sapphire samples (crystalline) was absent in samples implanted to similar fluences at $77 \mathrm{~K}$ but which were amorphous ${ }^{29}$. This component was ascribed to isolated iron ions or to ions associated with one or two oxygen vacancies. Otherwise, the spectra contained the same components as the room temperature samples, but in different proportions. About $20-22 \%$ of the implanted Fe was present as $\mathrm{Fe}^{0}$ for the entire range of fluence $\left(10^{16}\right.$ to $10^{17}$ ions $\left./ \mathrm{cm}^{2}\right)$.

The CEMS spectra for samples of sapphire amorphized by room temperature implantation of tin show the presence of Sn(II) and $\mathrm{Sn}(\mathrm{IV})^{17}$. One structural model of amorphous tin oxide consists of distorted octahedra having central Sn(IV) linked by $\mathrm{Sn}-\mathrm{O}$ bonds with bridging $\mathrm{Sn}(\mathrm{II})$ at the apex of a pyramid.

Short-range order in the "amorphous" phases was obtained from the fine structure of the electron energy loss spectra ${ }^{16}$. The radial distribution function, which gives the Al-O nearest-neighbor distances, was obtained from an analysis of such spectra 


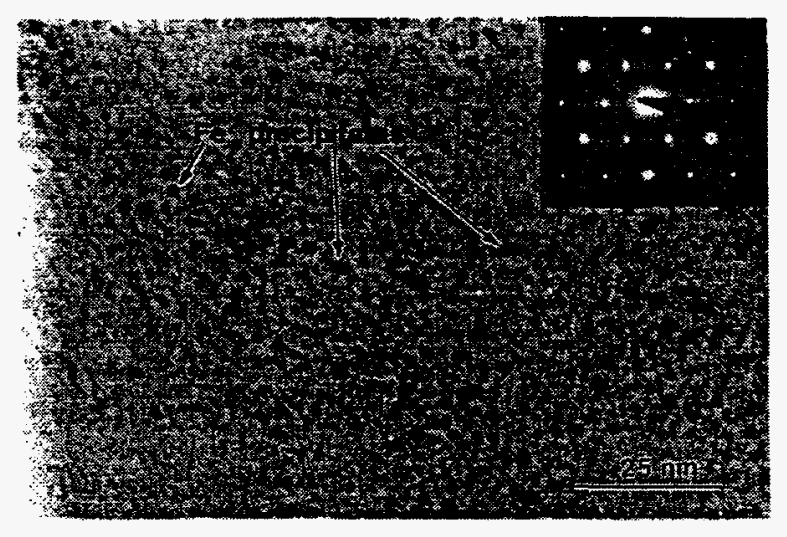

(a)

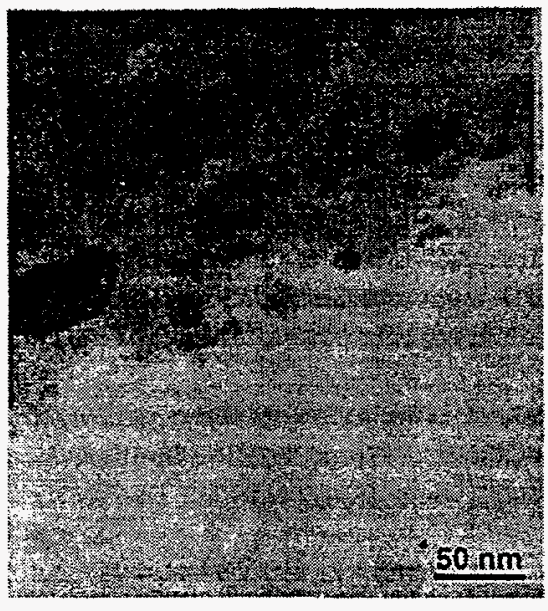

(b)

Fig. 7. TEM photograph of sapphire implanted with $1 \times 10^{17} \mathrm{Fe} / \mathrm{cm}^{2}(160 \mathrm{keV})$ at room temperature; (a) as-implanted, plan view; (b) annealed $1 \mathrm{~h} 1373 \mathrm{~K}$ in $\mathrm{Ar}-4 \% \mathrm{H}^{2}$, cross-section.

for samples implanted with $\mathrm{Al}+\mathrm{O}$ and $\mathrm{Fe}$ at $77 \mathrm{~K}$. Short-range order was found in both samples, and the details of the SRO depend upon the implanted species. The Al-O first near-neighbor distance in amorphous stoichiometric-implanted sample was similar to that found in $\gamma-\mathrm{Al}_{2} \mathrm{O}_{3}$, whereas, in the amorphous Fe-implanted sample it was that of $\alpha-\mathrm{Al}_{2} \mathrm{O}_{3}$.

\section{NANOMETER SIZE IRON DISPERSIONS IN SAPPHIRE}

The study of materials having the dimensions of a few nanometers has become possible in recent years due to the development of techniques to prepare clusters and colloids of metals and semiconductors of this size. Dispersions of nanometer size clusters or colloids in polymers or insulators offer the opportunity to study the boundary of the metallic state, i.e., at what size do the physical properties pass from those of giant molecules to those of the metallic (or semiconducting) state?

Ion implantation of metallic and semiconducting elements into insulators offers a unique opportunity to prepare nanometer size dispersions in crystalline or amorphous matrices. The size, shape and composition of such dispersed particles can often be further altered in a controlled manner by post-implantation annealing in selected atmospheres.

Because of the extremely low solubility of impurities in sapphire, there must be charge compensation for the excess (implanted) cations. This may be accomplished by formation of impurity-point defect complexes at low fluences ${ }^{28}$ and/or the formation of a metallic phase at higher fluences ${ }^{28,31}$. Metal-ceramic nanocomposite surface layers which may have unique properties can be prepared in this manner. This section summarizes studies on nanometer-size iron particles in sapphire prepared by ion implantation and post-implantation annealing ${ }^{14,28,31-33}$.

The CEMS study ${ }^{28}$ indicated that all implanted iron was in the $\mathrm{Fe}^{2+}$ state, probably associated with vacancy clusters, for fluences below $2 \times 10^{16} \mathrm{Fe} / \mathrm{cm}^{2}(160 \mathrm{keV})$. Optical absorption and luminescence measurements indicated large concentrations of $\mathrm{F}$ - and $\mathrm{F}^{+}$-centers (oxygen vacancies with two or one trapped electrons, respectively). Second phase particles were not detected in specimens implanted with $4 \times 10^{16} \mathrm{Fe} / \mathrm{cm}^{2}$ or less, although the CEMS measurements indicate $18 \%$ of the implanted ions were in the $\mathrm{Fe}^{0}$ state. The volume fraction of metallic particles would be about 0.02 and the probably of detection by electron microscopy is low. Second phase particles were clearly visible in micrographs taken of these samples annealed for one hour in a reducing atmosphere $\left(\mathrm{Ar}-4 \% \mathrm{H}_{2}\right)$ at 1173 to $1373 \mathrm{~K}$. The second phase particles, ranging in size 
from 5 to $25 \mathrm{~nm}$, were iron, according to energy dispersive x-ray spectroscopy (EDS). The largest particles are located near the peak implanted iron concentration and the size decreases as the concentration falls from this peak. Each particle located within $70-90 \mathrm{~nm}$ of the surface was associated with an attached void.

The RBS-C spectra for the sample implanted with $1 \times 10^{17} \mathrm{Fe} / \mathrm{cm}^{2}$ showed that the sapphire remained crystalline but was highly damaged in the peak damage region. The CEMS study indicated that $40-45 \%$ of the implanted iron was present in the metallic state for this fluence. After removal of approximately $50 \mathrm{~nm}$ from the implanted surface before the specimen was back-thinned, a distribution of small, darkly imaging clusters 1 to $3 \mathrm{~nm}$ in size was detected by electron microscopy, Fig. 7a. Measurements by EDS with a 2 to $3 \mathrm{~nm}$ diameter electron probe showed the clusters to be iron-rich and the diffuse satellite spots in the selected area diffraction (SAD) pattern were consistent with the clusters being $\alpha$-Fe. Lattice fringes in HREM confirmed the RBS findings that the matrix remained crystalline at this fluence.

If the $1 \mathrm{~nm}$ diameter Fe particles were spherical, each particle would contain about 45 iron atoms, or about 1200 atoms for the $3 \mathrm{~nm}$ diameter particles. The iron exhibited superparamagnetic behavior at room temperature but magnetic hyperfine splitting at $4.2 \mathrm{~K}$ with a field of $330 \mathrm{kOe}$.

- Cross-section micrographs of samples annealed at $1373 \mathrm{~K}$ contained images of elongated iron precipitates which were 40 to $60 \mathrm{~nm}$ long and up to $40 \mathrm{~nm}$ wide, Fig. $7 \mathrm{~b}$. The long dimension was parallel to the surface and centered at the location of the peak iron concentration. Smaller precipitates were found deeper into the specimen and closer to the surface. The size distribution shows one group peaked at $17 \mathrm{~nm}$ and extending to 35 to $40 \mathrm{~nm}$ and another group ranging from 33 to more than $58 \mathrm{~nm}$ with a maximum at $45 \mathrm{~nm}$. The large particles exhibited a tendency toward faceting. The long direction of the particles was parallel to the (0001) plane of sapphire. Elongation could be due to rapid diffusion parallel to these close-packed planes, or could be driven by concentration gradient of the implanted iron, e. g., more rapid growth along the line of highest concentration.

Random and channeled RBS spectra from the Al-sublattice for a specimen implanted with $2 \times 10^{17} \mathrm{Fe} / \mathrm{cm}^{2}$ coincided to a depth of about $260 \mathrm{~nm}$, indicating an amorphous or microcrystalline surface layer. The coincidence of the aligned and random spectra of iron in also suggests the random distribution of iron ions. Examination by TEM confirmed that the sapphire matrix was amorphous. Low magnification electron micrographs gave the impression of "strings" of iron particles lying parallel to the surface. High resolution electron micrographs (e.g., Fig. 8a) showed these 5-10 nm diameter particles to be crystalline and embedded in an amorphous matrix. Electron diffraction confirmed that they were $\alpha$-Fe. Lattice fringes and electron diffraction showed that the particles were oriented relative to the substrate; hence, the particles initially precipitated while the matrix was still crystalline. The orientation relationship is: $\{011\} \alpha_{-\mathrm{Fe}} \|\{001\}_{\text {sapphire }}$ and $\langle 111\rangle \alpha_{\text {-Fe }} \|$ $\langle 310\rangle_{\text {sapphire }}$. Lattice fringes in the iron particles indicated alignment with three $\langle 310\rangle$ directions of sapphire. The closepacked directions of iron and sapphire are not quite parallel, probably due to the misfit strains. The misfit strain is $4.3 \%$ along $[1 \overline{1} 0]$ (or [1 100$]$ ) and $17 \%$ along [110] (or [11 $\overline{2} 0]$ ) of sapphire.

Electron micrographs of samples implanted with $2 \times 10^{17} \mathrm{Fe} / \mathrm{cm}^{2}$ and annealed at $1173 \mathrm{~K}$ showed a band of iron 25 to 35 $\mathrm{nm}$ wide at a depth of $50 \mathrm{~nm}$, Fig. 8b. Many of these platelets extended for several hundred nanometers parallel to the surface. The region between the platelets still contained amorphous material. Some of the light appearing regions may also be cracks introduced by the difference in thermal expansion of the iron and the matrix or a coalescence of vacancies. Elliptical $\alpha$-Fe particles of 10 to $40 \mathrm{~nm}$ in length were also present. The long direction of the platelets was again parallel to the (0001) plane of sapphire. A similar pattern of iron platelets and large particles was observed in samples annealed at $1373 \mathrm{~K}$. Lattice fringes in these micrographs indicated that the amorphous matrix had recrystallized during annealing at 1173 and $1373 \mathrm{~K}$.

\section{OPTICAL PROPERTIES OF IMPLANTED SAPPHIRE}

The optical properties of sapphire are sensitive to the defect structure produced by ion implantation. These properties are also affected by the distribution and form of the implanted species. Figure 9 illustrates the effects of different implanted species on the infrared transmittance of $1 \mathrm{~mm}$-thick sapphire (c-axis parallel to the light beam ${ }^{34}$. The controlled sample had been optically polished and annealed for 5 days in flowing oxygen at $1500^{\circ} \mathrm{C}$. The effects of implantation on transmittance increase as the wave length decreases toward the visible spectrum. With the exception of $\mathrm{Ga}$, the decrease in transmittance at $3 \mu \mathrm{m}$ was 1.5 to $2 \%$. There was little change with ion fluence in the range of $1-10 \times 10^{16}$ ions $/ \mathrm{cm}^{2}$. 


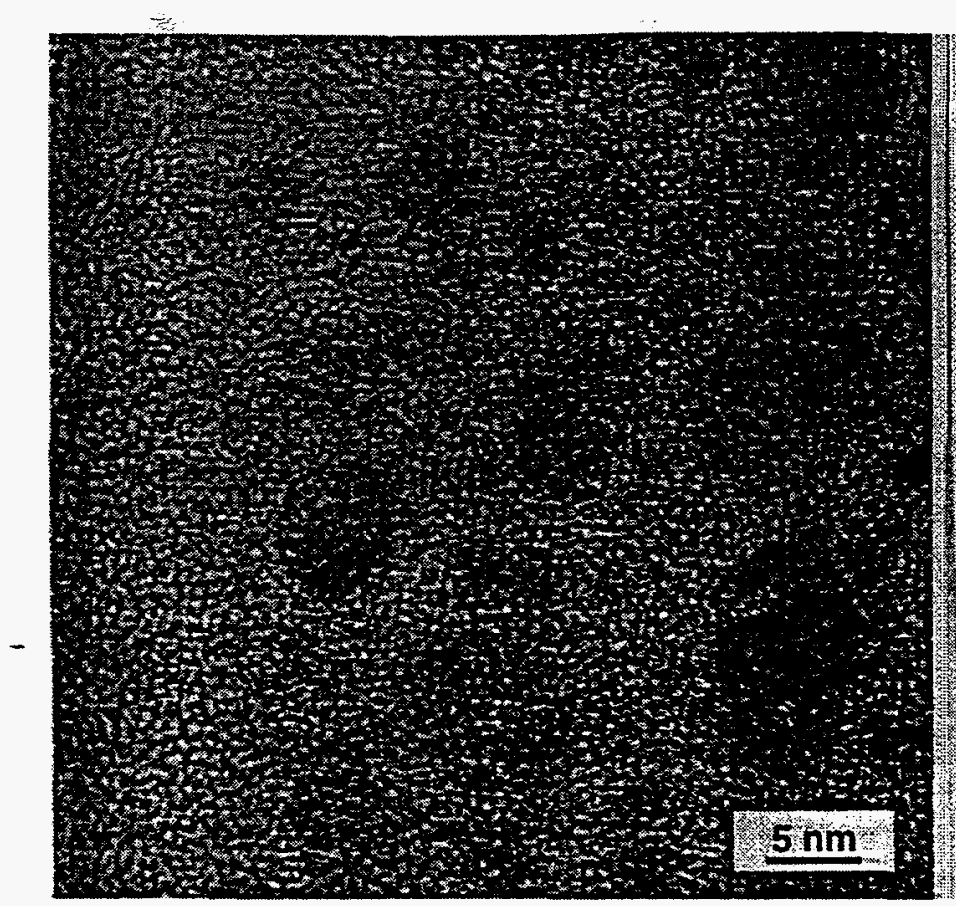

(a)

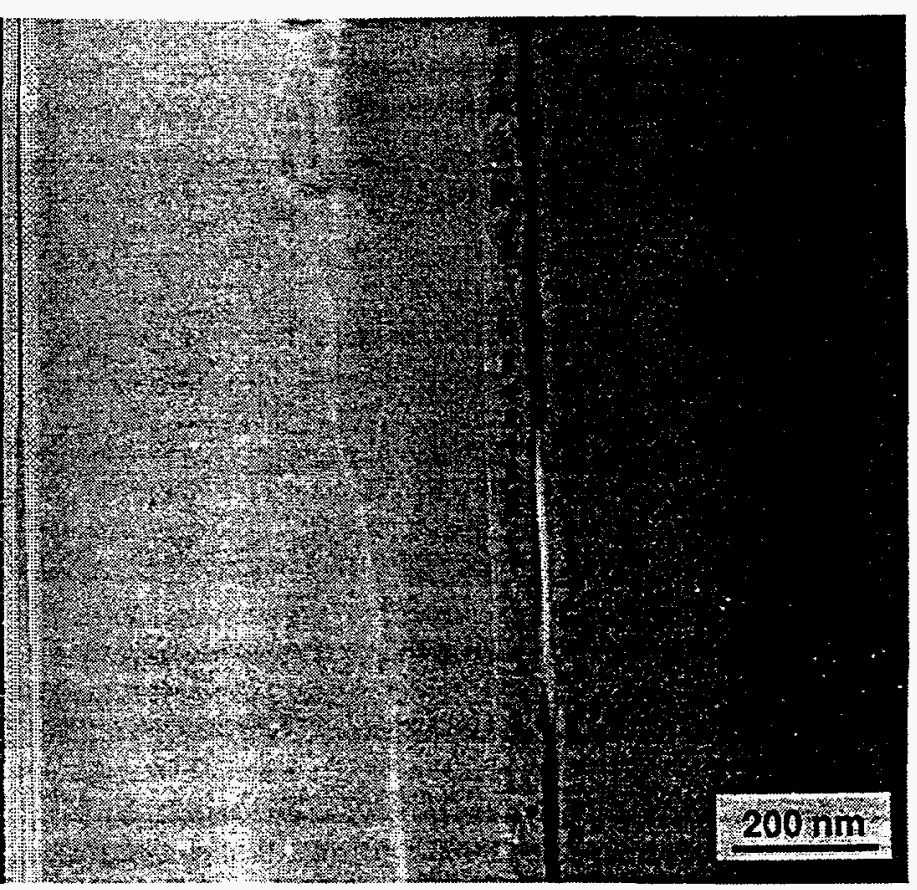

(b)

Fig. 8. TEM photograph of sapphire implanted with $2 \times 10^{17} \mathrm{Fe} / \mathrm{cm}^{2}(160 \mathrm{keV}$ ) at room temperature; (a) as-implanted; (b) annealed $1 \mathrm{~h}$ at $1173 \mathrm{~K}$ in $\mathrm{Ar}-4 \% \mathrm{H}_{2}$ (cross-section views).

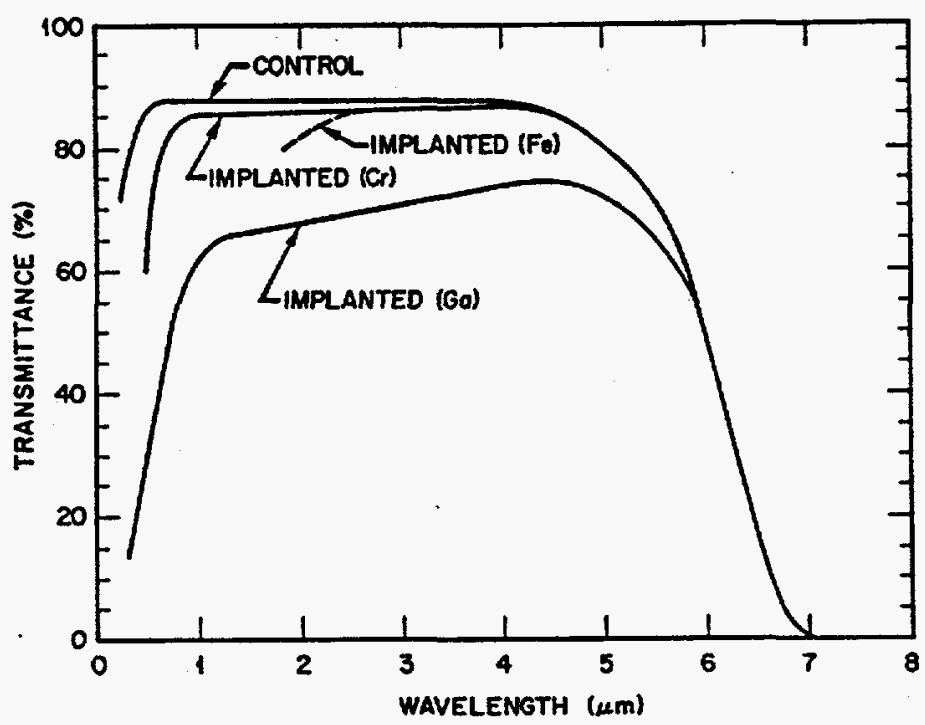

Fig. 9. Transmittance for annealed and implanted sapphire crystals.

The phase change from crystalline to amorphous caused by ion implantation of sapphire has been used to produce wave guides. The transformation to the amorphous structure is accompanied by a volume expansion of $20-25 \%$. This leads to a change in the refractive index of $1.3 \%$ which is sufficient for wave guide fabrication ${ }^{35}$. Using the concept that some ions efficiency trap implantation-produced defects and that the defects have reduced mobility at low temperatures, Townsend et al. 


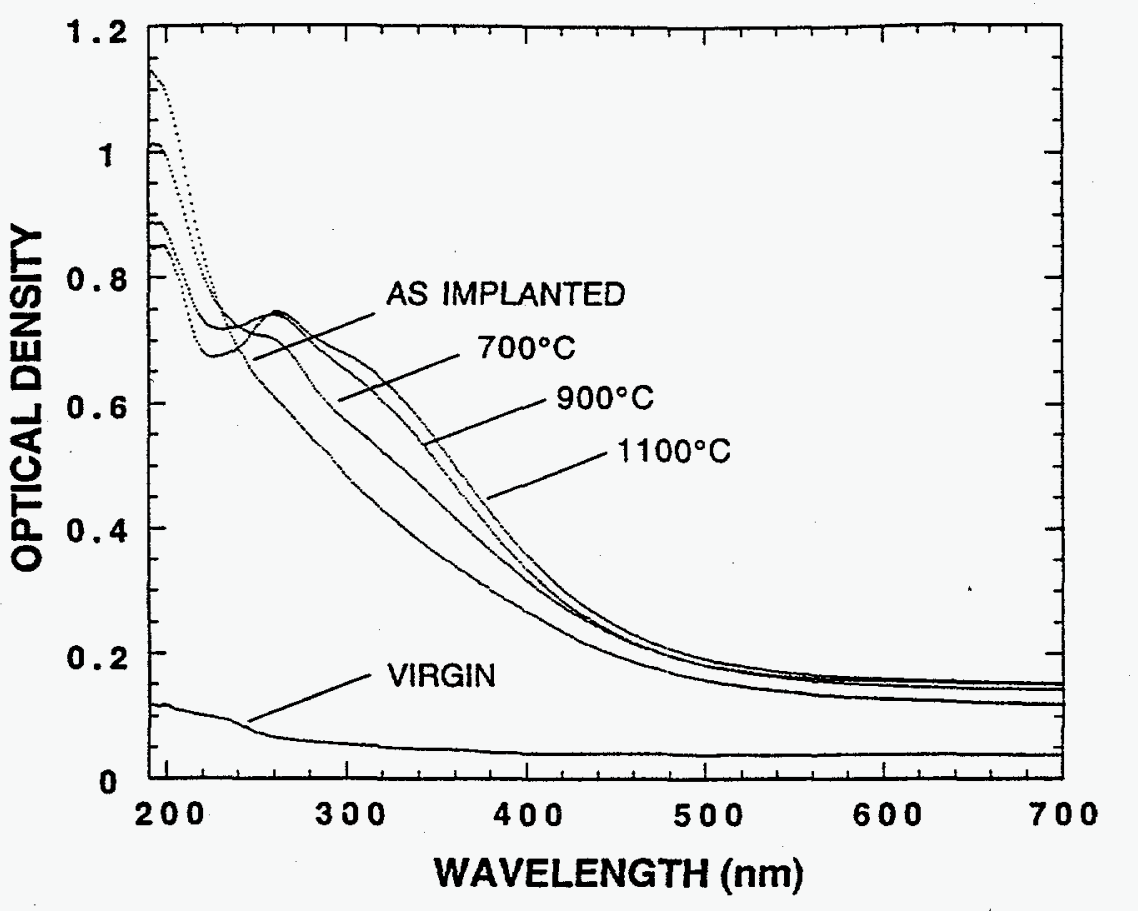

Fig. 10. Optical absorption of sapphire implanted with $1 \times 10^{17} \mathrm{Fe} / \mathrm{cm}^{2}$ and annealed in $\mathrm{Ar}-4 \% \mathrm{H}$ for $1 \mathrm{~h}$ at the indicated temperature.

produced a buried amorphous layer by implantating $6 \mathrm{MeV}$ carbon ions at fluences of $10^{16}$ to $5 \times 10^{16}$ ions $/ \mathrm{cm}^{2}$ at $77 \mathrm{~K}$. Waveguide profiles were analyzed at 488 and $633 \mathrm{~nm}$ using dark mode measurements. In all cases dark modes were observed with a depth of the barrier beneath the surface of $2.8 \mu \mathrm{m}$ which is very near the position of peak damage production.

Optical absorption spectra for the samples implanted with $1 \times 1017 \mathrm{Fe} / \mathrm{cm}^{2}$ and those annealed in the reducing atmosphere are contained in Fig. 10. The strong absorption band at about $200 \mathrm{~nm}$ is due to F-centers $\left(\mathrm{F}-\right.$ and $\mathrm{F}^{+}$). The optical density of this band, which is proportional to the concentration of the F-centers, decreases as the annealing temperature is increased. Annealing produces two additional peaks in the spectra, one at about $265 \mathrm{~nm}$ and a broad band in the range of 320 to 360 $\mathrm{nm}$. The $\mathrm{F}^{+}$-center has absorption peaks at 229 and $256 \mathrm{~nm}$ in addition to the one at $197 \mathrm{~nm}^{36}$; however, the intensity of this peak increases with annealing temperature and the absorption at $197 \mathrm{~nm}$ decreases. The TEM photographs show the size of iron precipitates to increase with annealing time and temperature and to exhibit a bimodal distribution of sizes. The absorption in this range is attributed to Mie scattering from the iron particles.

\section{SUMMARY}

The structure of ion implanted sapphire may be crystalline with point defects, point defect-impurity complexes, and dislocations or it may be amorphous. The structure depends upon the implantation parameters of ion species, ion fluence, substrate temperature and orientation of the ion beam relative to the crystallographic axes. The amorphous state contains short-range order whose details is affected by ion species. In general, the lower the temperature and higher the fluence, the more disorder that is retained. Certain ion species appear to stabilize the disorder against dynamic recovery during implantation and thus promote the amorphization.

Changes in chemical, physical and mechanical properties reflect changes in the structure. In this paper, changes in optical properties were described. 


\section{ACKNOWLEDGMENTS}

These studies were supported in part by the U. S. Department of Energy, Division of Materials Sciences under contract DEAC05-96OR22464 with Lockheed Martin Energy Research Corporation and by the Center for Materials Processing, University of Tennessee.

\section{REFERENCES}

1. S. J. Zinkle and C. Kinoshita, J. Nucl. Mater., 251 (1997) 200.

2. D. G. Walker, J. Nucl. Mater., 14 (1964) 195.

3. G. B. Kreft, W. Beezhold and E. P. EerNise, IEEE Trans. in Nucl. Sci., NS-32 (1975) 2247.

4. G. B. Kreft, J. Vac. Sci. Tech., 14 (1977) 533.

5. G. W. Arnold, G. B. Kreft and C. B. Norris, Appl. Phys. Lett., 25 (1974) 540.

6. G. B. Kreft and E. P. EerNise, J. Appl. Phys., 49 (1978) 2725.

7. S. J. Zinkle, Nucl. Instr. Meth. in Phys. Res. B91 (1994) 234.

8. S. J. Zinkle, J. Nucl. Mater. 219 (1996) 113.

9. S. J. Zinkle and L. L. Snead, Nucl. Instr. Meth. in Phys. Res. B116 (1996) 92.

10. S. J. Zinkle, in T. Diaz de la Rubia, L. W. Hobbs, I. M. Robertson and G. S. Was (eds.) Microstructual Evolution During Irradiation, (Materials Research Society, Pittsburgh, PA, 1997)

11. C. W. White, C. J. McHargue, P. S. Sklad, L. A. Boatner and G. C. Farlow, Mater. Sci. Reports, 4 (1989) 43.

12. C. M. Davisson and I. Manning, NRL Report 8859, Naval Research Laboratory, Washington, DC, 1986.

13. S. J. Bull, Ph. D. Dissertation, Cambridg University (UK) (1988).

14. S. X. Ren, C. J. McHargue, L. F. Allard, Y. Chen, J. D. Hunn, B. N. Lucas and R. K. Williams, in I. M. Robertson, L. E. Rehn, S. J. Zinkle and W. J. Phythian (eds.), Microstructure of Irradiated Materials, (Materials Research Society, Pittsburgh, PA, 1995) 305.

15. C. J. McHargue, G. C. Farlow, C. W. White, J. M. Williams, B. R. Appleton and H. Naramoto, Mater. Sci. Eng., 69 (1985) 123.

16. C. J. McHargue, P. S. Sklad and P. Angelini, in P. Borgesen, J. A. Knapp and R. A. Zhur (eds.), Beam-Solid Interactions: Physical Phenomena, (Materials Research Society, Pittsburgh, PA, 1990) 505.

17. C. J. McHargue, P. S. Sklad, J. C. McCullum, C. W. White, A. Perez and G. Marest, , ibid .555.

18. H. Naramoto, C. W. White, J. M. Williams, C. J. McHargue, O. W. Holland, M. M. Abaham and B. R. Appleton, J. Appl. Phys., 54 (1983) 683.

19. H. Abe, S. Yamamoto and H. Naramoto, Nucl. Instr. Meth. in Phys. Res. B127/128 (1997) 170.

20. G. C. Farlow, P. S. Sklad, C. W. White, C. J. McHargue and B. R. Appleton, in Y. Chen, W. D. Kingerly and R. J. Stokes (eds.), Defect Properties and Processing of High-Technology Nonmetallic Materials, (Materials Research Society, Pittsburgh, PA,1986) 387.

21. M. E. O'Hern, L. J. Romana. C. J. McHargue, J. C. McCallum and C. W. White, in R. Stoller, A. Kumar and D. Gelles (eds.) Effects of Radiation in Materials (ASTMSTP 1125, ASTM, Philadelphia, PA, 1992) 740.

22. C. J. McHargue, M. E. O'Hern, C. W. White and M. B. Lewis, Mater. Sci. Eng., Al15 (1989) 361.

23. A. Turos, Hj. Matzke and P. Rabette, Phys. Stat. Sol. (a), 64 (1981) 565.

24. A. V. Drigo, S. LoRusso, P. Mazzoldi, P. D. Goode and N. E. W. Hartley, Radiat. Eff., 33 (1977) 161.

25. A. Carnera, A. V. Drigo and P. Mazzoldi, , Radiat. Eff., 30 (1980) 29.

26. G. C. Farlow, C. J. McHargue, P. S. Sklad and C. W. White, J. Mater. Res., 5 (1990) 1502.

27, S. J. Zinkle, in C. J. McHargue, R. Kossowsky and W. O. Hofer (eds.), Structure- Property Relationships in SurfaceModified Ceramics, (Kluwer Academic Press, Dordrecht, 1989) 215.

28. C. J. McHargue, C. W. White, P. S. Sklad, A. Perez and G. Marest, J. Mater. Res., 6 (1991) 2145.

29. C. J. McHargue, C. W. White, P. S. Sklad, A. Perez and G. Marest, J. Mater. Res., 6 (1991) 2160.

30. C. J. McHargue, C. W. White, B. R. Appleton, G. C. Farlow and J. M. Williams, Materials Research Society Symposium Processings, 27 (1984) 385.

31. L. J. Romana, P. Thevenard, S. Ramos, B. Canut, L. Gea, M. Brunel, L. L. Horton and C. J. McHargue, J. Surfaces and Coatings, 51 (1996) 410.

32. S. X. Ren, Ph. D. dissertation, University of Tennessee, Knoxville, TN (1995).

33. C. J. McHargue, S. X. Ren, P. S. Sklad, L. F. Allard and J. Hunn, Nucl. Instr. Meth. Phys. Res. B116 (1996) 173.

34. C. J. McHargue and W. B. Snyder, SPIE 2018 (1993) 135.

35. P. D. Townsend, P. J. Chandler, R. A. Wood, L. Zhang, J. C. McCallum and C. J. McHargue, Electronics Letters, 25 (1990) 1193.

36. F. Agullo-Lopez, C. R. A. Catlow and P. D. Townsend, Point Defects in Materials (Academic Press, London, 1988) 159. 